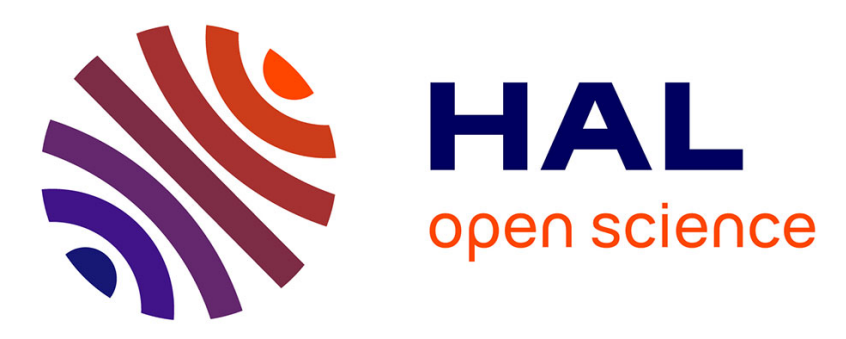

\title{
The first disaggregated solar atlas of Djibouti: A decision-making tool for solar systems integration in the energy scheme
}

Benjamin Pillot, Marc Muselli, Philippe Poggi, Pierrick Haurant, Idriss Hared

\section{- To cite this version:}

Benjamin Pillot, Marc Muselli, Philippe Poggi, Pierrick Haurant, Idriss Hared. The first disaggregated solar atlas of Djibouti: A decision-making tool for solar systems integration in the energy scheme. Renewable Energy, 2013, 57, pp.57-69. 10.1016/j.renene.2013.01.030 . hal-00801458

\section{HAL Id: hal-00801458 https://hal.science/hal-00801458}

Submitted on 16 Mar 2013

HAL is a multi-disciplinary open access archive for the deposit and dissemination of scientific research documents, whether they are published or not. The documents may come from teaching and research institutions in France or abroad, or from public or private research centers.
L'archive ouverte pluridisciplinaire HAL, est destinée au dépôt et à la diffusion de documents scientifiques de niveau recherche, publiés ou non, émanant des établissements d'enseignement et de recherche français ou étrangers, des laboratoires publics ou privés. 


\title{
The first disaggregated solar atlas of Djibouti: a decision-making tool for solar systems integration in the energy scheme
}

Benjamin Pillot ${ }^{1 \star}$, Marc Muselli ${ }^{1}$, Philippe Poggi ${ }^{1}$, Pierrick Haurant ${ }^{1}$, Idriss Hared $^{2}$

${ }^{1}$ Université de Corse, UMR CNRS 6134 SPE, Route des Sanguinaires, 20000 Ajaccio, France; Email: pillot@univ-corse.fr; marc.muselli@univ-corse.fr; philippe.poggi@univ-corse.fr; haurant@univ-corse.fr

${ }^{2}$ Centre d'Etudes et de Recherche de Djibouti, Route de l'aéroport, B.P. 486 Djibouti, République de Djibouti

Email: ihared1@yahoo.fr

•Corresponding author; Email: pillot@ univ-corse.fr, Mobile: +33 (0)6 284947 32; Tel.: +33 (0)4 955241

30; fax: +33 (0)4 95453328

Paper length: 6403 words (including introduction, main text and conclusion)

\begin{abstract}
Nowadays, energy supply is a major challenge for developing countries. In Sub-Saharan Africa, about only one third of the population is connected to the electrical network and the use of classical energy resources presents economical and environmental problems. As many other African countries, the Djiboutian
\end{abstract}


government looks for installing power systems using renewable energies, including solar systems, in order to overcome power supply difficulties in their energetic strategy.

Therefore, the aim of this study is the creation of the first solar atlas in Djibouti, including assessment and improvement, for helping to establish an energy planning. To realize this atlas, a satellite-based irradiance model is used (EUMETSAT O\&SI SAF). To validate this model over Djibouti, we installed 2 pyranometric weather stations during the year 2010 and we compared hourly, daily and monthly irradiation estimates against ground measurements. Results showed a good agreement between measurements and estimates, with, for the whole hourly sets, a RRMSE equal to $10.88 \%$ and $15.29 \%$, and a bias of $0.61 \%$ and $-2.17 \%$. Then, to improve accuracy of irradiation estimates, we disaggregated irradiation maps with a 3 arc second ( 90 meters at the equator) Digital Elevation Model (DEM), in order to take into consideration topography and elevation effects. As current software does not allow downscaling of pre processed maps, we performed this work by computing our own global model, combination of horizon, elevation correction and irradiance splitting models. By comparing horizon estimates against measured horizons, we observed that error probability on irradiation increased over high mountainous areas, mainly due to the original DEM error. Finally, according to the final computed atlas, during the year 2010, mean irradiation all over the country was around $2100 \mathrm{kWh} / \mathrm{m}^{2}$ and about $82 \%$ of the country received over $2000 \mathrm{kWh} / \mathrm{m}^{2}$. Furthermore, the solar radiation reaching Djibouti corresponded to 20000 times the total yearly energy consumption of the country in 2005.

With the first solar atlas of Djibouti, this study shows how reliable the solar potential in the country is and presents an accurate decision-making tool for sizing future solar systems across the country.

Keywords: Africa, Disaggregation, Djibouti, Energy planning, Ground measurements, Satellite-based solar atlas

\section{Nomenclatures}


Top of Atmosphere (TOA) albedo

narrowband to broadband conversion coefficient

$C$

radiometer count

$c_{\text {offset }} \quad$ calibration offset of SEVIRI level 1.5 header $\left(\mathrm{mW} \mathrm{m}^{-2} \mathrm{sr}^{-1}\left(\mathrm{~cm}^{-1}\right)^{-1}\right)$

cal $_{\text {slope }} \quad$ calibration slope of SEVIRI level 1.5 header $\left(\mathrm{mW} \mathrm{m}^{-2} \mathrm{sr}^{-1}\left(\mathrm{~cm}^{-1}\right)^{-1}\right)$

$d_{k} \quad$ calculated distance from observer point to the horizon $\mathrm{k}$ point $(\mathrm{m})$

$E_{0} \quad$ solar constant $\left(1358.2 \mathrm{~W} / \mathrm{m}^{2}\right)$

$f$

radiance to reflectance factor $\left(21.21 \mathrm{~mW} \mathrm{~m}^{-2} \mathrm{sr}^{-1}\left(\mathrm{~cm}^{-1}\right)^{-1}\right)$

$f_{\text {aniso }} \quad$ anisotropic factor or Bi-directional Reflectance Distribution Function (BRDF)

$G_{0} \quad$ global horizontal extraterrestrial irradiance $\left(\mathrm{W} / \mathrm{m}^{2}\right)$

$G_{h} \quad$ global horizontal irradiance $\left(\mathrm{W} / \mathrm{m}^{2}\right)$

$G_{h, \text { shading }}(z)$ DEM-based global horizontal irradiance, taking into account shadowing effects $\left(\mathrm{W} / \mathrm{m}^{2}\right)$

$I_{i} \quad$ ith measured global horizontal irradiation value $\left(\mathrm{Wh} / \mathrm{m}^{2}\right)$

$\bar{I} \quad$ measured global horizontal irradiation mean value $\left(\mathrm{Wh} / \mathrm{m}^{2}\right)$

$I_{i}^{\prime} \quad$ ith estimated global horizontal irradiation value $\left(\mathrm{Wh} / \mathrm{m}^{2}\right)$

$\overline{I^{\prime}} \quad$ estimated global horizontal irradiation mean value $\left(\mathrm{Wh} / \mathrm{m}^{2}\right)$

$I_{h, \text { shading }}(z) \quad$ DEM-based global horizontal irradiation, taking into account shadowing effects $\left(\mathrm{Wh} / \mathrm{m}^{2}\right)$

j day of the year

$k_{d} \quad$ diffuse fraction

$k_{t} \quad$ clearness index

$L_{S C} \quad$ scaled radiance (unitless)

M narrowband to broadband conversion coefficient

$R \quad$ broadband reflectance (unitless) 


\begin{tabular}{|c|c|}
\hline$R_{D E M}$ & local average DEM resolution (m) \\
\hline$R_{n b}$ & narrowband reflectance (unitless) \\
\hline$S_{b}$ & direct shading factor \\
\hline$S_{d, h}$ & isotropic horizontal diffuse shading factor \\
\hline$S_{\text {horizon }}$ & average error sensitivity coefficient \\
\hline$T_{1}$ & sun-surface atmospheric transmittance (unitless) \\
\hline$T_{a}$ & clear sky atmospheric transmittance (unitless) \\
\hline$T_{c l}$ & cloud factor (unitless) \\
\hline$z$ & DEM elevation $(\mathrm{m})$ \\
\hline$z_{0}$ & mean GTOPO30 elevation (m) \\
\hline$\alpha$ & horizon elevation angle (rad) \\
\hline$\alpha_{k}$ & horizon elevation angle of the $\mathrm{k}$ point (deg) \\
\hline$\alpha_{H}^{\gamma_{S}}$ & horizon elevation angle in the sun azimuth angle direction (rad) \\
\hline$\alpha_{S}^{\gamma_{s}}$ & sun elevation angle in the sun azimuth angle direction (rad) \\
\hline$\gamma$ & horizon azimuth angle (rad) \\
\hline$\gamma_{S}$ & sun azimuth angle (rad) \\
\hline$\theta_{0}$ & sun zenith angle (rad) \\
\hline$v(j)$ & corrective term describing Earth-sun distance seasonal variation (unitless) \\
\hline$\tau(z)$ & optical thickness of the atmosphere \\
\hline
\end{tabular}

\section{Introduction}

Nowadays, the energy supply of stand-alone populations is one of the greatest challenges for developing countries. This is particularly true for Africa. When electricity does not reach 2 billion people in the world 
[1], Sub-Saharan Africa stays the least electrified region of the globe with only one third of households connected to the network [2,3]. Furthermore, a large number of African countries has faced recurrent power supply utility crisis over the past years, when oil price was increasing constantly [4]. Finally, when remote populations can't access fuel and electricity, the massive use of other classical energy resources, like fuelwood, often destroys environment dramatically and causes severe socio-economic troubles [5]. This particular framework of permanent energy crisis incited African governments to find alternative solutions, including renewable energies. Africa presents a great availability of renewable resources [5], which are a reliable solution for an economical and sustainable development, especially for remote and rural populations $[2,4,5]$. Hence, small-scale and large-scale integration of the renewable energies within the African energy layout is part of the main policies across the continent $[4,6]$.

The Republic of Djibouti is a $23200 \mathrm{~km}^{2}$ little country, located in the Horn of Africa, which perfectly symbolizes the energy challenge in Sub-Saharan Africa. The electrical production was around $270 \mathrm{GWh}$ in 2003 and the total installed power of the electrical network is, at present time, about $130 \mathrm{MW}$, mainly constituted by 2 fuel thermal power plants located in the capital. Their available power was about $60 \%$ in 2007, producing great instability in electrical distribution, and the electrification rate is very low (about 30 $\%)$, generating a large amount of scattered remote areas throughout the country [7]. At last, vegetation covers only $3.2 \%$ of the country and timber resources are very sparse, restraining energy supply alternatives for rural populations. Therefore, energy is a main purpose of the Djiboutian government's policy. However, renewable energy integration is still low (about $0.2 \%$ of the total installed power), although great geothermal and solar potential does exist [7]. If geothermal energy should permit an important centralized electrical production in the future, solar energy presents very interesting stand alone applications, as, for instance, photovoltaic electrification, including Solar Home Systems (SHS) [8], solar thermal electrification, concentrating solar power [9,10], or solar cooking as an alternative to the use of fuel and fuel-wood [7,11]. Nevertheless, to perform an accurate integration of these solar systems into the Djibouti's energy development scheme, it is necessary to know exactly the solar resource and its geographical distribution over the country. Consequently, as no solar study has ever been realized in the country, this work presents the first solar atlas of Djibouti. 
At the moment, Africa's solar mapping remains complicated, especially due to the lack of long timeseries ground data [12]. Some solar potential studies exist about Sub-Saharan Africa [13-15] but still present limited subsequent applications. In Djibouti, no solar mapping study has been yet achieved because of the lack of ground solar data [7]. Nevertheless, many models have been developed in order to derive irradiance from instantaneous satellite images. From a strictly scientific point of view, for a solar mapping process, satellite-based irradiance data are more accurate than an interpolation of ground data [16,17]. From logistics consideration, satellite data are essential in a country like Djibouti, where any pyranometer and meteorological networks don't exist [7] and where cost, maintenance or material safety are important restrictions to a modern temporary meteorological network deployment.

Therefore, in this work, we used the Surface Solar Irradiance algorithm (SSI), an hourly satellite-based irradiance model developed by the European Organisation for the Exploitation of Meteorological Satellites (EUMETSAT) Ocean and Sea Ice Satellite Application Facility (O\&SI SAF). The aim of this study was the creation of the first Djibouti's solar energy atlas of global horizontal irradiation and one of the main upcoming objectives, to size PV systems [18] and other solar systems across the country. So, the better time and spatial resolutions of solar maps are, the more accurate the solar system sizing will be. The temporal resolution of the solar atlas was predetermined by the irradiance model hourly time step. Then, according to Ruiz-Arias et al. [19] and Bosch et al. [20], it was possible to improve irradiance accuracy and spatial resolution by using a Digital Elevation Model (DEM) in order to take into account the topography effects. Hence, we developed a disaggregation methodology, including development and assessment of a new fast horizon algorithm, in order to produce the first downscaled hourly global horizontal irradiation atlas of the Republic of Djibouti.

This paper is divided into two main parts. Firstly, the solar computation quality assessment is presented, by comparing estimated data against ground data measured by temporary weather stations deployed during the year 2010, in collaboration with the "Centre d'Etudes et de Recherche de Djibouti" (CERD), the national Djiboutian Science laboratory. Secondly, the disaggregation methodology is presented, and results of the whole disaggregated solar mapping computation are, finally, exposed. 


\section{Quality assessment of the O\&SI SAF satellite-based irradiance model over Djibouti}

\subsection{The Surface Solar Irradiance algorithm}

\subsubsection{The EUMETSAT Ocean \& Sea Ice Satellite Application Facility}

EUMETSAT has created a Satellite Application Facilities (SAF) network to take benefits from specialized scientific expertise at national meteorological institutes across the member states in Europe. SAF are based on cooperation between several institutes and hosted by a National Meteorological Service. The EUMETSAT O\&SI SAF was created in 1997 and is constituted by Météo-France, as host institute, Met. No (Norway), DMI (Denmark), Ifremer (France), KNMI (Netherlands) and SMHI (Sweden). It is specialized in both production and distribution of satellite-derived products, characterizing the ocean surface and radiative fluxes over the sea surface, as wind, sea ice characteristics, Sea Surface Temperature (SST), Downward Longwave Irradiance (DLI) and, the one we used in this work, the Surface Solar Irradiance product (SSI) $[21,22]$.

\subsubsection{The MSG-2/Meteosat 9 satellite}

The MSG-2/Meteosat 9 satellite is, at present time, the satellite used to estimate SSI over our study area, from the Meteosat Second Generation program (MSG) established under cooperation between ESA (European Space Agency) and EUMETSAT. It consists of a series of 4 geostationary meteorological satellites. The first MSG satellite, MSG-1/Meteosat 8, was launched on August $28^{\text {th }} 2002$. The second, MSG-2, was launched from Kourou (French Guyana) on December $22^{\text {nd }} 2005$ and is located, in its nominal position, over the equator at $0^{\circ}$ longitude. The continuous observation of the Earth disk is achieved by the main instrument boarded on the satellite, the 12-channel Spinning Enhanced Visible and Infrared Imager (SEVIRI) imaging radiometer. The full disk image has 3712 x 3712 pixels. A nominal image repeat cycle by SEVIRI, of about 15 minutes, consists of the full Earth disk imaging of about 12 minutes, line by line, from 
east to west and south to north, followed by the calibration of thermal IR channels and the scan mirror retrace $[23,24]$.

\subsubsection{Description of the O\&SI SAF SSI processing scheme}

The SSI algorithm is a physical model developed by the EUMETSAT O\&SI SAF [25,26], which has been controlled and validated against in situ data in many places around the world [27,28] and which is fully described in a product manual intended for users [29]. The data production processing scheme has been completely operational since July 2004 and SSI products are available through the Meteo-France server, ftp.meteo.fr. Thus, as a large documentation dataset already exists, we're just going to explain the basic statements of the model.

The SSI algorithm is a physical parameterization which, applied to every pixel of a satellite image, produces instantaneous fields of the global horizontal solar radiation $\left(\mathrm{W} / \mathrm{m}^{2}\right)$ reaching the Earth in the band 0.3-4 $\mu \mathrm{m}$. SSI products corresponding to our study area have a 0.1 degree spatial resolution in longitude and latitude and are called hourly SSI because of the MSG image process time sampling.

The SSI model combines a main processing scheme using the satellite visible channel input, and different auxiliary parameters (fixed atlas, monthly climatology and instantaneous fields). It can be summarized as follow:

- Re-mapping of the MSG-2 satellite image, at satellite resolution, onto the $0.1^{\circ} \mathrm{SSI}$ grid.

- Calibration of the SEVIRI 0.6 $\mu \mathrm{m}$ visible channel (Conversion of the satellite visible count into a bidirectional reflectance):

$$
\begin{aligned}
& L_{S C}=\left(\text { cal }_{\text {offset }}+\text { cal }_{\text {slope }} C\right) / f \\
& v(j)=1+0.0334 \cos [2 \pi(j-2) / 365.25]
\end{aligned}
$$




$$
R_{n b}=L_{S C} /\left[v(j) \cos \theta_{0}\right]
$$

Within Eq. (1), the scaled radiance $L_{S C}$ corresponds to the radiance, measured by SEVIRI, divided by the top of atmosphere effective solar irradiance, i.e. the top of atmosphere solar irradiance convoluted with the spectral response function of the satellite radiometer filter. $c a l_{\text {offset }}, c a l_{\text {slope }}$ and $f$ are specific MSG-2 radiometer calibration coefficients. Result of this calibration is a narrowband bi-directional reflectance $R_{n b}$ specific to the spectral filter of the SEVIRI radiometer (Eq. (3)).

- Radiometer spectral filter narrowband to solar spectrum broadband conversion:

$$
R=M R_{n b}+B
$$

The Pinker and Laszlo [30] linear formula (4) converts the radiometer narrowband reflectance $R_{n b}$ to the solar spectrum broadband reflectance $R . M$ and $B$ are coefficients depending on the scene type (ocean, vegetation, desert, cloud over ocean, cloud over vegetation and cloud over desert).

- Anisotropy correction, where broadband bi-directional reflectance is converted to Top of Atmosphere (TOA) albedo, which is independent of the satellite viewing angle:

$$
A\left(\theta_{0}\right)=R / f_{\text {aniso }}
$$

This correction is based on the formulae proposed by Manalo-Smith et al. [31]. The anisotropic factor $f_{\text {aniso }}$ is an analytical function of the viewing angles (sun zenith angle, satellite zenith angle and relative azimuth angle between satellite and sun viewing angle) depending on the scene type.

- Physical parameterization for clear and cloudy skies, where SSI is a function of TOA albedo and atmospheric transmittance:

$$
S S I=E_{0} v(j) \cos \theta_{0} T_{a} \text { in clear case }
$$




$$
S S I=E_{0} v(j) \cos \theta_{0} T_{1} T_{c l} \text { in cloudy case }
$$

Clear case uses the Frouin and Chertock [32] parameterization. Cloudy case is fully described in Brisson et al. [26].

Auxiliary inputs deriving from fixed atlas are the land-sea-coast pixel type, the mean altitude over the pixel (derived from a GTOPO30 Digital Elevation Model) and the prevailing land surface type. Monthly climatologic fields contain broadband surface albedo over land, water vapor content, ozone content and horizontal visibility. Instantaneous fields include predicted water vapor content from ARPEGE meteorological model, and cloud type and cover.

Note that MSG images, where the sun zenith angle is greater than $80^{\circ}$ and satellite zenith angle is greater than $75^{\circ}$, are unprocessed.

The SSI scheme presents some limits. The $0.1^{\circ}$ spatial resolution may be too low against the irradiance variability of mountainous or cloudy regions. Furthermore, re-mapping of the satellite image onto the SSI grid consists of averaging satellite pixels over a SSI pixel and, therefore, can limit accurate irradiance estimation over mixed/coast pixels, i.e. pixels including ocean and land surfaces. At last, hourly time resolution may restraint some subsequent solar applications.

For this work, we retrieved a reduced study area, covering a geographic square between $10^{\circ} \mathrm{N}$ and $15^{\circ} \mathrm{N}$ latitude and between $40^{\circ} \mathrm{E}$ and $45^{\circ} \mathrm{E}$ longitude. Finally, in order to focus on Djibouti, we limited this area between $10.9^{\circ} \mathrm{N}$ and $12.8^{\circ} \mathrm{N}$ latitude and between $41.7^{\circ} \mathrm{E}$ and $43.5^{\circ} \mathrm{E}$ longitude, corresponding to a 19 lines by 18 columns matrix. Figure 1.A. presents the study area with the corresponding SSI spatial grid.

\subsection{Evaluation of the O\&SI SAF SSI algorithm with ground data}

\subsubsection{Weather stations deployment}


Stations utilized for the O\&SI SAF SSI algorithm operational validation [28] present a great geographical covering disparity. Indeed, these stations are highly distributed in mid latitudes (Europe and North America), poorly distributed over the equator and low latitudes (Antilles and French Guyana), only one being located in southern hemisphere (South Africa) and none of them near Djibouti. Hence, as there is no pyranometric network existing whatsoever in Djibouti, we deployed, during the year 2010 and in cooperation with the CERD, two Vantage Pro 2 Davis Instruments temporary weather stations across the country, in order to assess and validate global solar horizontal radiation estimated through the SSI model. These stations use silicon pyranometers (reference $\mathrm{n}^{\circ} 6450$; precision $= \pm 5 \%$; spectral range $=0.4-1.1 \mu \mathrm{m}$; value range $=0-1800 \mathrm{~W} / \mathrm{m}^{2}$; temperature coefficient $=-0.12 \% /{ }^{\circ} \mathrm{C}$ ) and other standard sensors (temperature, relative humidity, pressure, wind speed and rain gauge). The selection of the 2 weather station sites was influenced by several important requirements. Firstly, from a solar radiation point of view, we had to install the stations in places corresponding to both distant and quite different climatologically SSI pixels. Secondly, for security reasons, it was necessary to select safe places, as public schools or administrations. Finally, the last constraint was about logistics, as station data had to be accessed quickly and permanently. For all these reasons, we decided to position the first station in the CERD at Djibouti-city (weather station 1; measuring period: 04/06/2010 - 12/30/2010) and the second station, in the prefecture of Dikhil, in the South West country (weather station 2; measuring period: 06/27/2010 - 01/09/2011), corresponding to "coast" and "land" type SSI pixels, respectively. Proportion of missing data corresponds to 5\% for station 1 and $16.2 \%$ for station 2. Figure 1.A shows location of the 2 temporary stations.

\subsubsection{Comparison between estimated and measured data: method and results}

In order to evaluate the SSI model over the study area, we compared irradiation data rather than irradiance data, for energy reasons mainly but also for technical reasons. On one hand, as mentioned in the introduction, the purpose of this study is the creation of the Djibouti's solar energy atlas in order to size solar systems across the country, including stand-alone PV systems [18]. So, it was necessary to compute accurate energy data with the best possible time step. In our case, this step was fixed by the hourly SSI time 
resolution and allowed to produce, at best, hourly irradiation maps. On the other hand, the current stations present a technical limit with irradiance data averaging over the selected time interval, which depends on the station accessibility (time step of 5 and 10 minutes for station 1 and station 2, respectively). Thus, validation method by using irradiation data not only assesses the whole solar energy map process but also avoids some additional errors.

Then, to properly interpolate and integrate SSI data, it was necessary to know the exact registration time of the MSG image over the study area. This time depends on the location of the study area and on the starting time of the satellite image acquisition. In our case, SSI model is based on MSG images which begin to be scanned by the SEVIRI imaging radiometer at HH:15 UTC. As Djibouti is located around the $2200^{\text {th }}$ line of the satellite image ( $3712 \times 3712$ pixels), the registration time corresponds approximately to HH:23 UTC. Hence, all computed hourly SSI data correspond to 4:23, 5:23, 6:23, 7:23, 8:23, 9:23, 10:23, 11:23, 12:23, 13:23 and 14:23 UTC. MSG images corresponding to 3:23 and 15:23 UTC are still unprocessed because of a sun zenith angle greater than $80^{\circ}$ over the year.

To control SSI model's validity and accuracy over the study area, we used some well known statistical indices, including Root Mean Square Error (RMSE), Mean Bias Error (MBE) and Correlation Coefficient (CC), defined as follow:

$$
\begin{aligned}
& R M S E=\sqrt{\frac{\sum_{i=1}^{n}\left(I_{i}^{\prime}-I_{i}\right)^{2}}{N}}\left(\mathrm{Wh} / \mathrm{m}^{2}\right) \\
& M B E=\sqrt{\frac{\sum_{i=1}^{n}\left(I_{i}^{\prime}-I_{i}\right)}{N}\left(\mathrm{Wh} / \mathrm{m}^{2}\right)} \\
& C C=\frac{\sum_{i=1}^{n}\left(I_{i}-\bar{I}\right)\left(I_{i}^{\prime}-\overline{I^{\prime}}\right)}{\sqrt{\sum_{i=1}^{n}\left(I_{i}-\bar{I}\right)^{2} \sum_{i=1}^{n}\left(I_{i}^{\prime}-\overline{I^{\prime}}\right)^{2}}}\left(\mathrm{Wh} / \mathrm{m}^{2}\right)
\end{aligned}
$$

And their relative contribution, Relative Root Mean Square Error (RRMSE) and Relative Mean Bias Error (RMBE), defined as: 


$$
R M B E=M B E / \bar{I}(\%)
$$

We considered 2 approaches to the irradiation data comparison. At first, to evaluate SSI process through the solar atlas computation, we limited the dataset to valid days, i.e. days without any missing or erroneous irradiance data and from which unprocessed data (sun zenith angle greater than $80^{\circ}$ ) were removed. Then, to estimate real error on the entire solar cartography computation, we considered all days, integrated between real sunrise and sunset hours, where missing, erroneous and unprocessed irradiance data were retrieved by linearly interpolating the corresponding clearness index data. This second method increased the hourly data sample used for comparison of $28.5 \%$ and $29.4 \%$ for station 1 and station 2 , respectively. Table 1 presents results of the evaluation method, for both stations. As monthly and daily irradiations correspond to the sum of hourly irradiations, RMBE is the same for all the presented irradiation datasets.

Station 2 presents the best results for all sets. Furthermore, for both the restricted and whole set, solar atlas computation slightly overestimates and underestimates irradiation for Dikhil and Djibouti-city, respectively, and presents, obviously, the best results for monthly comparison. Finally, the whole set consideration amplifies error in a limited way.

Thus, for the restricted set, daily RRMSE is about $4.5 \%$ for station 2 against $8.8 \%$ for station 1 . Bias is close to zero for both stations (1.36\% for Dikhil and $-2.01 \%$ for Djibouti-city) and station 2 presents a daily CC of about 0.95 against 0.86 for station 1 . Hourly irradiation data comparison reasonably increases RRMSE for both stations (9.52\% and $13.72 \%$ for Dikhil and Djibouti-city, respectively).

For the whole set, station 2 presents lower daily RRMSE and RMBE (4.28\% and $0.61 \%$ ), as they stay constants for station 1 (8.88\% and $-2.17 \%)$, while daily CC increases for Dikhil (0.9544) and decreases for Djibouti-city (0.8526). At last, the whole hourly dataset presents a RRMSE greater than the restricted hourly dataset for both stations (10.88\% and $15.29 \%$ for Dikhil and Djibouti-city, respectively) and also a better CC because of the concentration of added data at the beginning and at the end of the day. 
Pixel type ("land/sea") and frequent cloudy spells over the capital, because of the sea and the Intertropical Convergence Zone (ITCZ) proximity, coupled with hourly time step and low spatial resolution, explain results for the station 1 .

Scatter plots for valid days, presented in figure 2, confirm this data profile tendency, with good correlation between satellite-based model and ground measurements for monthly, daily and hourly irradiation at Dikhil, while the comparison for Djibouti-city presents data more scattered on both side of the 1-to-1 line. For the monthly scatter plots especially, the more distant points from the 1-to-1 line correspond to April and May, the cloudiest months.

To conclude, in spite of low spatial and temporal SSI resolutions, the complete process error is low for highquality pixels (i.e. "land" pixels with constant meteorological conditions) and remains acceptable for complex pixels (i.e. "mixed" pixels with more variable meteorological conditions than others). Although SSI products could be improved, principally with time resolution, to reduce meteorological variability effect, and spatial resolution, to reduce pixel surface type problem, they are acceptable over Djibouti, a country with preferential conditions, including a desert climate and a yearly global irradiation greater than $2000 \mathrm{kWh} / \mathrm{m}^{2}$.

\section{The downscaled solar atlas of the Republic of Djibouti}

This section presents the method we used to build the new disaggregated irradiation maps of the country. The methodology consists of the use of a 3 arc second Digital Elevation Model (DEM) in order to downscale SSI, at $0.1^{\circ}$ resolution, by considering topography, i.e. shadowing effects and intra-pixel variation of elevation. According to Ruiz-Arias et al. [19] and Bosch et al. [20], this method allows improving accuracy of the final solar atlas.

\subsection{Processing scheme}

In order to realize mapping disaggregation, we developed a specific program following the processing scheme described in figure 3. 
A lot of models describing terrain shadowing exist, at present time, and were implemented within software. Some of them just compute horizon for a given location, others combine horizon model with solar radiation estimate. Thus, many Geographical Information Systems (GIS) use their own DEM-based models to estimate solar radiation over mountainous areas [33]. Nevertheless, these GIS software still utilize simplified atmospheric parameterizations which limit their use for operational modeling $[19,33]$. In particular, they do not allow disaggregating external solar maps provided by another device. Therefore, to downscale satellitebased irradiance maps, it would have been necessary, on one hand, to compute horizon angle for each DEM pixel with a GIS or another specific device and, on the other hand, to realize irradiance splitting and elevation correction by programming models we selected. Such a processing scheme presents, obviously, important performance limitations. For these reasons, in order to avoid slow computation time due to both horizon modeling and data transfer between different programming languages, we preferred to implement a "3 in 1" global modeling program, combination of our own horizon model with elevation correction and irradiance splitting models. In comparison to the size of the whole dataset to process, this solution presented the highest possible computing efficiency.

As shown in figure 3, the 2 main inputs needed for the process are DEM and yearly timeseries of hourly SSI corresponding to the defined study area. The computation block calculates horizon, elevation correction and irradiance splitting for each DEM pixel over a year. Extraterrestrial irradiance and global atlas GTOPO30 are required to achieve elevation correction, while sun position is necessary to compute the beam shading factor. Then, extraterrestrial irradiance is also necessary to determine clearness index in order to split global irradiance into beam and diffuse components. Finally, after re-aggregation and integration, the computation block result is a yearly timeseries of disaggregated hourly irradiation for each DEM pixel. After all, result of the whole disaggregation process is the Djibouti's downscaled hourly irradiation atlas, i.e. a yearly timeseries of disaggregated hourly irradiation maps of the country.

The following sub-sections describe each processing step in detail and correspond to numbered gray sections within the computation block of figure 3 . 


\subsection{DEM downscaling}

\subsubsection{The Shuttle Radar Topography Mission}

Current DEMs were provided by the Shuttle Radar Topography Mission (SRTM), which occurred in February 2010, aboard the Endeavour space shuttle. By using Interferometric Synthetic Aperture Radar (InSAR), the mission recorded elevation data at 1 arc second resolution, from $80 \%$ of the Earth, between $60^{\circ} \mathrm{N}$ and $57^{\circ} \mathrm{S}[34,35]$. Voids due to lack of contrast in the radar image were filled in via a spatial filtering technique [36]. Finally, SRTM data were compiled by the Consultative Group for International Agriculture Research Consortium for Spatial Information (CGIAR-CSI) and are available through their web site [37]. SRTM data at 1 arc second resolution (SRTM-1) are available only for the USA, while SRTM data at 3 arc second resolution (SRTM-3) are available globally.

Figure 1.B shows the Djibouti's SRTM-3 DEM used in this work, corresponding to a $2221 \times 2041$ elevation matrix, comprised between $10.9^{\circ} \mathrm{N}$ and $12.75^{\circ} \mathrm{N}$ latitude, and between $41.75^{\circ} \mathrm{E}$ and $43.45^{\circ} \mathrm{E}$ longitude.

\subsubsection{Horizon modeling}

We developed our horizon model within a computing performance and flexibility strategy. In comparison to the great amount of processing data, it was necessary to conciliate horizon error and computing speed. For assessing and validating this model, we chose to compare, during the year 2010, estimations versus measured horizons in Corsica Island, France. Indeed, this island presents a high variety of topography patterns within a little area and, therefore, was an interesting region to retrieve a large diversified sample of measured horizons without difficulty.

To measure these horizons, we used a Builder 100 Leica Geosystems theodolite (azimuth angle accuracy: 9'; elevation angle accuracy: 6'), a very accurate instrument helping land surveyors to measure slope and aspect of a terrain. Furthermore, in order to evaluate computing efficiency, we compared our model against 2 other horizon models, the Carnaval Open Source, developed by the French desk study Incub, and r.horizon 
[38], part of the radiation model r.sun [39] implemented in the GRASS GIS Open Source. Carnaval uses France's SRTM-3 DEM already implemented within software and computes horizon for a given point, intended to be used later in a solar system sizing software. Our model and GRASS use SRTM-3 DEMs loaded by user. They are part of global models which compute, at last, DEM-based radiation maps, by using disaggregation for our model and the r.sun radiation model for GRASS. Note that r.horizon can be used in 2 different ways. On one hand, it can determine shadowing for a whole map by computing angular elevation in a specific azimuth direction. On the other hand, it can compute horizon for a given DEM pixel. It is this approach we chose for comparison. Among the 3 tested models, ours presents the lowest computation time before r.horizon and Carnaval, respectively. Moreover, as our horizon model has been directly incorporated within a global downscaling model, the total performance benefit is very important compared to the use of external models.

Finally, to realize this comparison study, we used RRMSE, RMBE and CC, the statistical indices defined in section 1.2.2.

Table 2 presents results of the comparison between measured horizons and horizons estimated through the 3 models. Our model and r.horizon present the more homogeneous correlation results for the whole set, with a CC equal to 0.9785 and 0.9765 , respectively. The 2 models provide close RRMSE ( $21 \%$ and $18.62 \%$ for our model and GRASS, respectively) while GRASS presents the best bias (-6.19\% against $-9.05 \%)$. At last, Carnaval shows the lowest quality results for the whole set with a CC equal to 0.8312, a RRMSE over 50\% and a negative bias of about $25 \%$. If we compare against the processing performance, our model is a good compromise between computation speed and horizon accuracy. Nevertheless, if we look at these results more carefully, we note that some horizons are well fitted by the models (for instance Bastia, Corte, Solenzara or Calvi) whereas some others present high relative errors. By neglecting some errors due to measures (errors on elevation measures or on the geo-referencing of the horizon site) or provided by horizon models, it is possible to explain and forecast the horizon absolute error by correlating it to the DEM original absolute error.

Let us consider a point of a given measured horizon. SRTM was expected to generate DEMs with a vertical RMSE of $16 \mathrm{~m}[34,35]$. Angular elevation absolute error on this point is, therefore, correlated to the distance 
between this point and the observer point. Moreover, although it is difficult to take into consideration, the lower the distance to the point is, the lower the number of DEM points describing this horizon is, for a given DEM resolution. So, if the horizon is strongly discontinued, the error probability will increase.

Then, according to Miliaresis et Paraschou [40] and Gorokhovich et Voustianiouk [41], vertical RMSE of DEMs is strongly dependent on the terrain slope. Thus, error is also linked to the elevation angle of the point. The last useful DEM parameter helping to predict model accuracy is, obviously, the DEM resolution. From these simple observations, in order to predict absolute error of a given horizon, we defined the following average error sensitivity coefficient:

$$
S_{\text {horizon }}=\frac{R_{D E M}}{N} \sum_{i=1}^{N} \frac{\alpha_{k}}{d_{k}}
$$

where $N$ is the number of measured points. Hence, the higher the coefficient $S_{\text {horizon }}$ is, the more important the error on the modeled horizon will probably be. To verify validity of such a coefficient, we observed evolution of both RMSE and MBE of the whole set with $S_{\text {horizon }}$, for our model, r.horizon and Carnaval. The model robustness study, shown in figure 4, presents both the error sensitivity analysis and the comparison between Corte and Tavignano, sites with $S_{\text {horizon }}$ equal to 0.14 and 6.86, respectively. The study shows, as expected, that RMSE increases with $S_{\text {horizon }}$. Moreover, at the same time, MBE decreases. The comparison between Corte and Tavignano illustrates this tendency. Horizon model fits Corte accurately when $S_{\text {horizon }}$ is low whereas the other site, with a high $S_{\text {horizon }}$, is, clearly, underestimated. However, studies realized by Miliaresis et Paraschou [40] in Crete, an island with similar topographic features than Corsica, and by Gorokhovich et Voustianiouk in the USA and Thailand [41], didn't show any underestimate error tendency. So, the resulting horizon error tendency was not really predictable. Consequently, we can conclude that horizon modeling step of the disaggregation process tends to underestimate or overestimate topography effects and, so, to overestimate or underestimate irradiation over regions where horizons are important, close or a combination of both.

\subsubsection{Elevation downscaling}


As mentioned in section 1.1.3., the SSI scheme takes altitude into consideration by using mean elevation derived from the 30 arc second GTOPO30 DEM. One SSI pixel uses the $12 \times 12$ elevation matrix average of the GTOPO30 DEM and corresponds to a $120 \times 120$ elevation matrix in the SRTM-3 DEM. Thus, the intra pixel elevation variance can be very high for some regions. So, to determine the global horizontal irradiance $G_{h}$ on a DEM pixel at an altitude $z$ from the mean GTOPO30 altitude $z_{0}$, we used the following empirical correction established by Wahab et al. [42] over the northern Africa:

$$
G_{h}(z)=G_{0} \exp (-\tau(z))
$$

where $\tau(z)$ characterizes the optical thickness of the atmosphere:

$$
\tau(z)=\tau\left(z_{0}\right) \beta^{\left(z_{0}-z\right)}, \beta=1.20
$$

with

$$
\tau\left(z_{0}\right)=-\ln \left(G_{h}\left(z_{0}\right) / G_{0}\right)
$$

Note that correction is available for all skies only when $z$ ranges from 0 to $3 \mathrm{~km}$, including the Djibouti's altitude range.

\subsection{Irradiance splitting and shading consideration}

To take into account shadowing effects, it was necessary to decompose global horizontal irradiance $G_{h}(z)$ into the beam horizontal and diffuse horizontal components, $G_{b, h}(z)$ and $G_{d, h}(z)$, by using a diffuse fraction model $k_{d}$, such as:

$$
\left\{\begin{array}{c}
G_{b, h}(z)=\left(1-k_{d}\right) G_{h}(z) \\
G_{d, h}(z)=k_{d} G_{h}(z)
\end{array}\right.
$$

However, if many empirical models have been established for splitting global irradiance and global irradiation, none of them have been validated over Djibouti. 
Hence, we have computed, in first order, several diffuse fraction models to observe final differences

between resulting solar maps. We used three models defined as functions of the only clearness index $k_{t}$.

Indeed, because of the great surface to process, we preferred to implement the least possible inputs in order to compute the complete solar atlas with high time calculation performances.

Firstly, we computed the Ruiz-Arias regressive diffuse fraction model [43] and the Erbs model [44], as they were already used within disaggregation methodologies $[19,20]$ and gave good results. Then, we compared these models to a third one, the CLIMED2 model [45], which gave accurate results over the north Mediterranean belt area, including Corsica Island [46].

Eq. (18), Eq. (19) and Eq. (20) present the Ruiz-Arias, Erbs and CLIMED2 models, respectively:

$$
\begin{aligned}
& k_{d}=0.952-1.041 \exp \left(2.300-4.702 k_{t}\right) \\
& k_{d}=\left\{\begin{array}{cl}
1-0.09 k_{t} & \text { for } 0 \leq k_{t} \leq 0.22 \\
0.9511-0.1604 k_{t}+4.388 k_{t}^{2} & \text { for } 0.22<k_{t} \leq 0.80 \\
-16.638 k_{t}^{3}+12.336 k_{t}^{4} & \\
0.165 & \text { for } k_{t}>0.80
\end{array}\right.
\end{aligned}
$$

$$
k_{d}=\left\{\begin{array}{cl}
0.995-0.081 k_{t} & \text { for } k_{t} \leq 0.21 \\
0.724+2.738 k_{t}-8.32 k_{t}^{2}+4.967 k_{t}^{3} & \text { for } 0.21 \leq k_{t} \leq 0.76 \\
0.180 & \text { for } k_{t}>0.76
\end{array}\right.
$$

where $k_{t}=G_{h}(z) / G_{0}$

Then, to consider shading effects, we computed the direct shading factor $S_{b}$ and the isotropic horizontal diffuse shading factor $S_{d, h}$, as described by Quaschning et Hanitsch [47].

If $\alpha_{S}^{\gamma_{S}}$ is the sun elevation angle in the sun azimuth angle direction $\gamma_{S}$ and $\alpha_{H}^{\gamma_{S}}$, the horizon elevation angle in the sun azimuth angle direction, the direct shading factor $S_{b}$ is described by the following Heaviside function: 


$$
S_{b}=H\left(\alpha_{S}^{\gamma_{S}}, \alpha_{H}^{\gamma_{S}}\right)=\left\{\begin{array}{cl}
0 & \text { if } \alpha_{S}^{\gamma_{S}}>\alpha_{H}^{\gamma_{S}} \\
1 / 2 & \text { if } \alpha_{S}^{\gamma_{S}}=\alpha_{H}^{\gamma_{S}} \\
1 & \text { if } \alpha_{S}^{\gamma_{S}}<\alpha_{H}^{\gamma_{S}}
\end{array}\right.
$$

The isotropic horizontal diffuse shading factor $S_{d, h}$ is defined as the ratio between the horizon projection surface on the hemisphere and the total hemisphere surface. For an object polygon, as shown in figure 5, with two ground vertices, $\left(\gamma_{1}, 0\right)$ and $\left(\gamma_{2}, 0\right)$, and two vertices $p_{1}$ and $p_{2}$ on the hemisphere that are connected by a line $\alpha(\gamma)=m \gamma+n$ with $m=\left(\alpha_{2}-\alpha_{1}\right) /\left(\gamma_{2}-\gamma_{1}\right)$ and $n=\left(\alpha_{1} \gamma_{2}-\alpha_{2} \gamma_{1}\right) /\left(\gamma_{2}-\gamma_{1}\right)$, the horizontal diffuse shading factor is equal to:

$$
\begin{aligned}
S_{d 1-2, h} & =\frac{\int_{\gamma_{1}}^{\gamma_{2}} \int_{0}^{m \gamma+n} \sin \alpha \cos \alpha d \alpha d \gamma}{\pi} \\
& =\left\{\begin{array}{cc}
\frac{1}{2}\left(\gamma_{2}-\gamma_{1}\right) \sin ^{2} \alpha_{1} & \text { for } m=0 \\
\frac{1}{\frac{2}{2}\left(\gamma_{2}-\gamma_{1}\right)\left(\frac{1}{2}+\frac{1}{4} \frac{\sin 2 \alpha_{1}-\sin 2 \alpha_{2}}{\alpha_{2}-\alpha_{1}}\right)} & \text { for } m \neq 0
\end{array}\right.
\end{aligned}
$$

At last, for an object with $\mathrm{n}$ vertices $p$, the isotropic horizontal diffuse shading factor becomes:

$$
S_{d, h}=\sum_{i=1}^{n-1} S_{d i-i+1, h}\left(p_{i}, p_{i+1}\right)
$$

After all, the global horizontal irradiance taking into account shadowing effects, $G_{h, \text { shading }}(z)$, is equal to:

$$
G_{h, \text { shading }}(z)=\left(1-k_{d}\right)\left(1-S_{b}\right) G_{h}(z)+k_{d}\left(1-S_{d, h}\right) G_{h}(z)
$$

By integrating this term over one hour, we get the new downscaled hourly irradiation, $I_{h, \text { shading }}(z)$, for the given DEM pixel:

$$
I_{h, \text { shading }}(z)=\int_{\text {hour }} G_{h, \text { shading }}
$$

At last, by computing the whole study area, we retrieved a yearly timeseries of downscaled hourly irradiation for each DEM pixel of the country, i.e. a yearly timeseries of downscaled hourly irradiation 
maps. Thus, in comparison to the hourly SSI inputs, outputs are hourly solar energy maps, taking into account shadowing and elevation variability effects and having a 3 arc second spatial resolution.

\subsection{Results}

All the results presented in this section derive from computation of the year 2010.

In order to evaluate hourly irradiation estimates over a day, figure 6 presents hourly irradiation maps for the $17 / 12 / 2010$ over a specific reduced area, between $11.4^{\circ}-12.2^{\circ}$ latitude and $42^{\circ}-43^{\circ}$ longitude, presenting a significant topography. We chose this day, as a day where sun elevation angle was the lowest and where clearness index was the highest possible, in order to optimize observation of shadowing effects. Note that, however, some original SSI pixels, forming "square-based" patterns, strongly stand out within the different hourly maps. It is simply explained by their original type, as these pixels were either "sea" or cloudy type and already stood out before downscaling. Hourly irradiation maps, at UTC time H, correspond to global horizontal irradiation reaching the surface between H-1 and H. Hours 4 and 5, where clearness index is low, mainly present diffuse shading effects. Direct shading effects are localized to hours close to sunrise and sunset. A great part of the day, between 7:00 and 11:00, presents only altitude correction effects. Also, some extreme lonely values, due to direct shading, still exist (around $200 \mathrm{Wh} / \mathrm{m}^{2}$ ) when solar elevation is the highest, between 8:00 and 10:00, and can be explained by the sensitivity analysis presented in part 3.2.2. Nevertheless, these values are very limited and actually remain hidden. They don't really affect the whole solar cartography.

Then, in order to estimate the global horizontal irradiation potential of Djibouti, we computed both yearly average and monthly average daily global irradiation maps, with and without disaggregation. Figure 7 presents both the processed yearly maps, with and without downscaling, and table 3 presents, at the same time, specifications of the monthly average daily irradiation maps with range values, means and standard deviations (std). When disaggregation is considered, table 3 describes results for all the diffuse fraction models presented in section 3.3. 
Analogous results between the 3 tested models are explained by the limited shadowing effects over the country. Firstly, as shown in figure 7.B, topography effects are localized to some regions. Then, for a day close to midwinter, figure 6 has shown that direct shading effects were restricted to hours near to sunset and sunrise. Furthermore, as clearness index was high over the year, diffuse shading effects were also limited. As Djibouti is near from equator, high sun trajectory over the year explains this specific fact. Therefore, except for the lowest monthly range values, the use of one diffuse fraction model rather than another is not significant. Considering disaggregation, methodology reduces mean and amplifies standard deviation and range very slightly. Obviously, solar irradiation all over the country quite remains the same, with or without disaggregation. Moreover, results show that disaggregation is not really monthly dependent, except for range values. The same causes producing the same effects, these results are explained by the spatial and temporal limitations of shadowing effects, and by the limitation of altitude correction, due to the high yearly clearness index.

Even so, although Djibouti is near from equator and has preferential solar conditions, some of the original SSI pixels are strongly downscaled, as shown in figure 7. Hence, depending on region features, disaggregation onto a 3 arc second spatial grid must be sparingly used. In order to avoid useless computations and, so, to obtain the best accuracy to performance ratio, such a disaggregation study must be a good balance between region location and size, solar conditions, topography characteristics and computing efficiency.

Also, we can extract some tendencies from these irradiation maps. Hence, March, April and May present the highest mean values over the country, because of a sun trajectory close to zenith. Low mean solar irradiations for July and August are explained by the presence of dust in the air, due to the "khamsin" sandstorm. At last, February is the month which seems to present the highest meteorological variability with the maximum standard deviation and the minimum mean of all the set.

Finally, with all the standard deviations less than $0.5 \mathrm{kWh} / \mathrm{m}^{2}$.day, and a range of mean values over the year between 4.72 and $6.28 \mathrm{kWh} / \mathrm{m}^{2}$.day, Djibouti presents low temporal and spatial variability of global irradiation. According to the final atlas, during the year 2010, mean global irradiation over the country was about $2100 \mathrm{kWh} / \mathrm{m}^{2}$ and about $82 \%$ of the country received over $2000 \mathrm{kWh} / \mathrm{m}^{2}$. Considering complete area, 
the total solar irradiation reaching the country was about $4.8410^{13} \mathrm{kWh}$, which represents about 20000 times the total Djiboutian yearly energy consumption in $2005\left(\sim 2.4210^{9} \mathrm{kWh}\right)[7]$.

As an opening on possible future works, the computation of direct horizontal irradiation gave some interesting results. Hence, according to these results, mean yearly beam irradiation over the country was around $1400 \mathrm{kWh} / \mathrm{m}^{2}$, equivalent to the yearly global irradiation reaching a sunny region like Corsica. About $77 \%$ of the country received a yearly direct irradiation over $1300 \mathrm{kWh} / \mathrm{m}^{2}$. Obviously, these results are given for information and the whole computation of direct horizontal, tilted and normal irradiation will be part of a future detailed work. Furthermore, if we consider grid-connected power solar systems, we can also observe that some "solar regions" balance each other. For instance, about $6 \%$ of the country yearly receives between 1900 and $1950 \mathrm{kWh} / \mathrm{m}^{2}$ when $6 \%$ receives between 2200 and $2250 \mathrm{kWh} / \mathrm{m}^{2}$. Hence, in order to ensure electrical network stability and avoid some electrical overload phenomena because of the intermittent nature of solar energy, integration of power solar systems within the grid will require a detailed co variability study of solar radiation map timeseries.

\section{Conclusion}

This work has presented the first downscaled solar atlas of the Republic of Djibouti, combining a satellitebased irradiance model, developed by the EUMETSAT O\&SI SAF, and a 3 arc second DEM retrieved from CGIAR-CSI web site.

The irradiance model validation step occurred during the year 2010 by deploying 2 weather stations across the country. Comparison between measurements and estimates has shown that current limits of the SSI model don't prevent results from remaining acceptable, with a maximum RRMSE of about $15 \%$, for the whole hourly dataset computation.

Following previous studies, we have used a SRTM-3 DEM to improve solar radiation maps, by considering shadowing effects and intra-pixel variability of elevation. As GIS software has not been developed to downscale pre-existing irradiance maps with DEMs, we have achieved a disaggregation process by combining our own horizon model with elevation correction and irradiance splitting models. The horizon 
accuracy assessment study, realized in Corsica Island during the year 2010, has shown that calculated horizons may induce irradiation error over high mountainous areas, mainly because of the original DEM error. Then, through the use of specific diffuse fraction models, combined with shading factors, we have computed the new downscaled hourly irradiation. Finally, we have exposed the first global horizontal irradiation maps of the country, with and without disaggregation. These maps clearly show how high the solar potential all over the country is, even when disaggregation is considered.

Energy is, at present time, one of the most important challenges in developing countries. With the $165^{\text {th }}$ rank on the Human Development Index (HDI) [48], Djibouti is a little country which perfectly symbolizes the Sub-Saharan way of life. Lack of energy supply contributes to maintain a high poverty level across the country, and limits development of stand-alone areas. Obviously, solar potential will not recover all current energy problems. However, according to the solar atlas presented in this work, solar systems represent one among other reliable solutions to the Djiboutian power supply crisis.

\section{Acknowledgements}

This work was made possible due to the Cooperation Agreement which has been established between the Environment Science Laboratory from University of Corsica and the CERD.

We thank the "Service d'Archivage et de Traitement Météorologiques des Observations Satellitaires" (SATMOS) program, managed by Meteo-France and the "Institut des Sciences de l'Univers" (INSU), for providing SSI products reshaped onto our study area.

We are also grateful to Mr. Abdoulkhader Khaireh and the other scientists from the CERD, for helping us to install weather stations and provide radiation data.

\section{References}

[1] J.M. Huacuz, L. Gunaratne, Photovoltaics and Development, in: Handbook of Photovoltaic Science and Engineering, Wiley, England, 2003, pp. 1043-1071.

[2] S. Karekezi, W. Kithyoma, Renewable energy strategies for rural Africa: is a PV-led renewable energy strategy the right approach for providing modern energy to the rural poor of sub-Saharan Africa?, Energy Policy 30 (2002) 1071-1086. 
[3] U. Deichmann, C. Meisner, S. Murray, D. Wheeler, The economics of renewable energy expansion in rural Sub-Saharan Africa, Energy Policy 39 (2011) 215-227.

[4] S. Karekezi, Renewables in Africa-meeting the energy needs of the poor, Energy Policy 30 (2002) 1059-1069.

[5] I.M. Bugaje, Renewable energy for sustainable development in Africa: a review, Renewable and Sustainable Energy Reviews 10 (2006) 603-612.

[6] T.C. Chineke, F.M. Ezike, Political will and collaboration for electric power reform through renewable energy in Africa, Energy Policy 38 (2010) 678-684.

[7] F. Ahmed Aye, Intégration des énergies renouvelables pour une politique énergétique durable à Djibouti, $\mathrm{PhD}$ thesis, Université de Corse, 2009.

[8] N. Wamukonya, Solar home system electrification as a viable technology option for Africa's development, Energy Policy 35 (2007) 6-14.

[9] F. Trieb, H. Mullersteinhagen, Concentrating solar power for seawater desalination in the Middle East and North Africa, Desalination 220 (2008) 165-183.

[10] P. Viebahn, Y. Lechon, F. Trieb, The potential role of concentrated solar power (CSP) in Africa and Europe - A dynamic assessment of technology development, cost development and life cycle inventories until 2050, Energy Policy In Press, Corrected Proof (2010).

[11] M. Wentzel, A. Pouris, The development impact of solar cookers: a review of solar cooking impact research in South Africa, Energy Policy 35 (2007) 1909-1919.

[12] L. Diabate, P. Blanc, L. Wald, Solar radiation climate in Africa, Solar Energy 76 (2004) 733-744.

[13] F. Drake, Y. Mulugetta, Assessment of solar and wind energy resources in Ethiopia. I. Solar energy, Solar Energy 57 (1996) 205-217.

[14] R. Munzhedzi, A.B. Sebitosi, Redrawing the solar map of South Africa for photovoltaic applications, Renewable Energy 34 (2009) 165-169.

[15] A. Madhlopa, Solar radiation climate in Malawi, Solar Energy 80 (2006) 1055-1057.

[16] R. Perez, R. Seals, A. Zelenka, Comparing satellite remote sensing and ground network measurements for the production of site/time specific irradiance data, Solar Energy 60 (1997) 89-96.

[17] M. Muselli, G. Notton, J.L. Canaletti, A. Louche, Utilization of Meteosat satellite-derived radiation data for integration of autonomous photovoltaic solar energy systems in remote areas, Energy Conversion and Management 39 (1998) 1-19.

[18] B. Pillot, M. Muselli, P. Poggi, Solar atlas implementation and planning of PV system off-grid electrification in Djibouti, in: Proceedings of the 25th European Photovoltaic Solar Energy Conference and the 5th World Conference on Photovoltaic Energy Conversion, Valencia, Spain, 2010. 
[19] J.A. Ruiz-Arias, T. Cebecauer, J. Tovar-Pescador, M. Súri, Spatial disaggregation of satellite-derived irradiance using a high-resolution digital elevation model, Solar Energy 84 (2010) 1644-1657.

[20] J.L. Bosch, F.J. Batlles, L.F. Zarzalejo, G. López, Solar resources estimation combining digital terrain models and satellite images techniques, Renewable Energy 35 (2010) 2853-2861.

[21] G. Guevel, Status of the OSI SAF, in: Proceedings of the 2007 EUMETSAT Meteorological Satellite Conference and the 15th Satellite Meteorology \& Oceanography Conference of the American Meteorological Society, Amsterdam, The Netherlands, 2007.

[22] G. Guevel, The EUMETSAT Ocean and Sea Ice SAF : Overview and Status, in: SAF Training Workshop, Ocean and Sea Ice Second Workshop, Perros-Guirec, France, 2005.

[23] J. Schmetz, P. Pili, S. Tjemkes, D. Just, J. Kerkmann, S. Rota, A. Ratier, An introduction to Meteosat second generation (MSG), Bulletin of the American Meteorological Society 83 (2002) 977-992.

[24] European Organisation for the Exploitation of Meteorological Satellites, Meteosat Data Collection and Retransmission Service, Darmstadt, Germany, 2009.

[25] P. Le Borgne, G. Legendre, A. Marsouin, OSI SAF Radiative fluxes, in: SAF Training Workshop, Ocean and Sea Ice Second Workshop, Perros-Guirec, France, 2005.

[26] A. Brisson, P. Le Borgne, A. Marsouin, Development of algorithms for surface solar irradiance retrieval at O\&SI SAF low and mid latitudes, Eumetsat Ocean and Sea Ice SAF internal project team report (1999).

[27] P. Le Borgne, G. Legendre, A. Marsouin, Validation of the OSI SAF radiative fluxes over the equatorial Atlantic during AMMA experiment, in: Proceedings of the 2007 EUMETSAT Meteorological Satellite Conference and the 15th Satellite Meteorology \& Oceanography Conference of the American Meteorological Society, Amsterdam, The Netherlands, 2007.

[28] P. Le Borgne, G. Legendre, A. Marsouin, Validation of the OSI SAF radiative fluxes, in: Proceedings of the 2006 EUMETSAT Meteorological Satellite Conference, Helsinki, Finland, 2006.

[29] Ocean \& Sea Ice Satellite Application Facility, Surface Solar Irradiance Product Manual, Product User Manual (2005).

[30] R.T. Pinker, I. Laszlo, Modeling surface solar irradiance for satellite applications on global scale, Journal of Applied Meteorology 31 (1992) 194-211.

[31] N. Manalo-Smith, G.L. Smith, S.N. Tiwari, W.F. Staylor, Analytic forms of bidirectional reflectance functions for application to Earth radiation budget studies, Journal of Geophysical Research 103 (1998) 19 733-19 751.

[32] R. Frouin, B. Chertock, A technique for global monitoring of net solar irradiance at the ocean surface. Part 1 : Model, Journal of Applied Meteorology 31 (1992) 1056-1066.

[33] J.A. Ruiz-Arias, J. Tovar-Pescador, D. Pozo-Vazquez, H. Alsamamra, A comparative analysis of DEM-based models to estimate the solar radiation in mountainous terrain, International Journal of Geographical Information Science 23 (2009) 1049-1076. 
[34] T.G. Farr, P.A. Rosen, E. Caro, R. Crippen, R. Duren, S. Hensley, M. Kobrick, M. Paller, E. Rodriguez, L. Roth, others, The shuttle radar topography mission, Reviews of Geophysics 45 (2007).

[35] B. Rabus, M. Eineder, A. Roth, R. Bamler, The shuttle radar topography mission--a new class of digital elevation models acquired by spaceborne radar, ISPRS Journal of Photogrammetry and Remote Sensing 57 (2003) 241-262.

[36] A. Jarvis, J. Rubiano, A. Nelson, A. Farrow, M. Mulligan, Practical use of SRTM data in the tropics: comparisons with digital elevation models generated from cartographic data, Working document 198 (2004) 32.

[37] A. Jarvis, H.I. Reuter, A. Nelson, E. Guevara, Hole-filled seamless SRTM data V4, International Centre for Tropical Agriculture (CIAT), available from http://srtm.csi.cgiar.org (last time accessed January, 2010).

[38] J. Hofierka, T. Huld, T. Cebecauer, M. Suri, Open Source Solar Radiation Tools for Environmental and Renewable Energy Applications, in: Proceedings of the International Symposium on Environmental Software Systems, Prague, Czech Republic, 2007.

[39] M. Šrí, J. Hofierka, A New GIS-based Solar Radiation Model and Its Application to Photovoltaic Assessments, Transactions in GIS 8 (2004) 175-190.

[40] G.C. Miliaresis, C.V.E. Paraschou, Vertical accuracy of the SRTM DTED level 1 of Crete, International Journal of Applied Earth Observation and Geoinformation 7 (2005) 49-59.

[41] Y. Gorokhovich, A. Voustianiouk, Accuracy assessment of the processed SRTM-based elevation data by CGIAR using field data from USA and Thailand and its relation to the terrain characteristics, Remote Sensing of Environment 104 (2006) $409-415$.

[42] M.A. Wahab, M. El-Metwally, R. Hassan, M. Lefevre, A. Oumbe, L. Wald, Assessing surface solar irradiance and its longterm variations in the northern Africa desert climate using Meteosat images, International Journal of Remote Sensing 31 (2010) 261-280.

[43] J.A. Ruiz-Arias, H. Alsamamra, J. Tovar-Pescador, D. Pozo-Vázquez, Proposal of a regressive model for the hourly diffuse solar radiation under all sky conditions, Energy Conversion and Management 51 (2010) 881-893.

[44] D.G. Erbs, S.A. Klein, J.A. Duffie, Estimation of the diffuse radiation fraction for hourly, daily and monthly-average global radiation, Solar Energy 28 (1982) 293 - 302.

[45] A. De Miguel, J. Bilbao, R. Aguiar, H. Kambezidis, E. Negro, Diffuse solar irradiation model evaluation in the north Mediterranean belt area, Solar Energy 70 (2001) 143-153.

[46] G. Notton, C. Cristofari, M. Muselli, P. Poggi, Calculation on an hourly basis of solar diffuse irradiations from global data for horizontal surfaces in Ajaccio, Energy Conversion and Management 45 (2004) 2849-2866.

[47] V. Quaschning, R. Hanitsch, Irradiance calculation on shaded surfaces, Solar Energy 62 (1998) 369-375.

[48] J. Klugman, Human development report 2011 - Sustainability and equity : a better future for all, United Nations Development Programme (UNDP), New York, USA, 2011. 